\title{
Violence against Pregnant Women - The Study Population in Salt City
}

\author{
Lubna Makhled Al-adayleh $^{1} \&$ Hana Husni Al Nabulsi ${ }^{1}$ \\ ${ }^{1}$ Department of social work, Al-Balqa Applied University, Al Salt, Jordan \\ Correspondence: Lubna Makhled Al-adayleh, Department of social work, Al-Balqa Applied University, Al Salt, \\ Jordan. E-mail: dhanalubna@yahoo.com
}

\author{
Received: October 19, 2012 Accepted: November 20, 2012 Online Published: January 28, 2013 \\ doi:10.5539/ass.v9n2p257 URL: http://dx.doi.org/10.5539/ass.v9n2p257
}

\begin{abstract}
This study aimed to identify the forms of violence against pregnant women represented in (physical violence, psychological, and social), as well as identifying the consequences of violence against pregnant women, also identifying the impact of some qualitative variables such as (level of education, housing, income level, family members). The forms of violence against a pregnant woman, and to identify the relationship between some qualitative variables and consequences of violence against pregnant women, a study in which consisted of 250 women from pregnant women attending antenatal clinics in the city of Salt in Jordan, was used package Statistical Social Sciences (SPSS).

The study was applied at statistical methods and simple statistics advanced test, to analysis of variance T-test and F-test, to show the differences and implications of statistical variables, the results revealed that the actions stressful work, being forced to have sex, and beating, is one of the most prevalent forms of physical violence. A Study also demonstrated that questioning the sex of the baby, neglecting, and the carelessness of the husband to towards the health status, was one of the most common forms of psychological violence known. The exposure of pregnant women to smoke, and the neglect of her husband because of being pregnant with a female and not allowing seeing the doctor was one of the forms of social violence. Also showed that stress, the anxiety and depression is the psychological effects of violence, also the slackness to perform house duties, and isolation forms other social impacts. The results also showed the presence of statistically significant relationships between forms of violence against a pregnant woman due to the variable places of residence, and monthly income. And there are no statistically significant differences to forms of violence attributed to the educational level.
\end{abstract}

Keywords: pregnant women, violence, psychological violence, social violence, physical violence

\section{Introduction}

There is no doubt that violence against women is a crime by all standards, and it remains negative impact on women for years and may continue with it throughout her life. The phenomenon of violence is spreading in all human societies, as well as in various social classes, which takes many forms that impact the vulnerable members of the family, because of it's effects of serious violence, the General Assembly proclaimed that the United Nations announced on December 17, 1999 on November 25 of each year the International Day for the Elimination of Violence against Women, also the Governments called the same decision, Internationals Organizations and Non-Governmental Organizations, to organize activities to increase awareness of the problem. (Gharaibeh Faisal, 2012).

Were a numerous definitions varied that deals with violence, each researcher reflect his view on the violence subject, where (Walter, 1997) identified violence as "All acts carried out by a family member, and damaging material or moral or both). Another member in the same family." (Alauwadh, 2002) identified violence against wife's as "A form of violence against women draw directly or indirectly to wife's, in order to deprive them from exercising their social rights, legal, economic, and subjected by force to control and harm them using intimidation, threats, abuse and deprivation,". "The World Health Organization, (2005) identified that "The deliberate use of physical force or power force, whether by threat or actual use of them, by a person against himself or against another person which leads to preponderance of the possibility of injury, or death, or mal development or deprivation".

(Abu Saeed 2012) Suggest that the definition of violence, based on social as "Any act which results or is likely to result harm or suffering physical, sexual or psychological for women, including threats of committing ,such an 
act or by forcing or abusive deprivation of freedom, whether occurring in public life or private." A number of theories tried to explain the violence incidence, as explained social detachment theory that violence as a behavior is learned by the individual through social environment, and the greater degree of approach between the individual and his environment, increases the learning capability and conviction to violent behavior, and this theory conceder families is the most environment that individual learn from, due to his interaction enduring with. (moon. Issam Tawfiq,2008).

The psychoanalytic theory illustrated that violence occurred to a disturbance in the individual's personality, because of the expertise and past experiences that influenced in childhood, and that there is a correlation between violence and instincts minimum in the individual. (Gharaibeh, Faisal, 2012). So women who experienced violence in childhood developed their believes that they deserve to be punished, and afraid to defend herself in front of the strongest which lead to submission to this treatment rather than confront it and causing her strong emotions against eligibility and efficiency. (Ghanem, Abdullah Abdul Ghani, 2004).

The theory of social disintegration sees that, the different standards that regulate behavior between different social units and which moves the individual in its interaction within the community, including family, school, community friends, and coworkers, so the inter-conflicts lead the individual to violence, and with the knowledge expand which will lead to a state of turmoil in the standards stock of knowledge, and if there is different standards between groups, that will lead to internal conflicts which lead to different patterns of violence. But social learning theory held that an individual acquires violence through learning, observation and imitation of the surrounding environment, whether in the family or school or through media, and that the individual in learning violent behaviors by imitating others, and what result from rewards and punishments, family may show violent behaviors as a worth behavior that don't deserves punishment, while the Impose Frustration theory confirmed that frustration produces aggressive motives to provoke behavior or ending in hurting others, and it fall gradually after the individual harm others, and this process is called Venting. (Ibrahim, Asma'a Badri, 2010).

The theory of sub-culture believes that common violence varies sub-culture is different from one society to another, and the violence is more acceptable in communities with poor socio-economic level, whereas violence is a means of method acceptable to resolve disputes and conflicts over communities with high socio-economic level. This theory sees that violence against women excesses is certain subcultures (Jazi, 2005). But the feminist Theory has interpreted the occurrence of violence on women, because of the nature of traditional expectations in the prevailing social order within the community which are linked to social genders which are based on gender inequality, and imposing the masculine role, which allows the use of violence against women in order to prevent her independence, her presence and increase her strength.

In this theory the Social Construction, support the husband domination. (National Council for Family Affairs, 2008) And the Radicalism feminist theories attributed that women's expose to violence rapidly to men and not to institutions (Brinkerhoft, 1997), stating Firestone that women oppression is rooted in the relationship between men and women, and this situation remains essentially without changing and with the pass of time they realize that the basis of the division is not economically, but gender and it's called male Dominance, the Paternal Regime (Kornemann, 1981), The Paternal Regime is a general social phenomenon of exploitation and subordination and control, Millet believed that men in a paternal society control his habit, because of the psychological effects, and the upbringing.

The ideology and the biological differences are used to confirm the oppression of women, when it made the roles domination belong to men and made the roles of dependency is the woman share, and that the relationship between men and women is basis on power and domination over women. (Azizi, 2005).

The Feminist Radicalism considers that the main institution in women persecution and scolding is the family, which helped the individual to learn its roles and their positions. Men need women through the house work that women do, as well as the advantage in depending on the free house work that the women do (Gidden, 2009).

The violence is a reflection to build strength exists on society in general, and women are considered the most vulnerable to violence for her weak situation within the family. violence is a harmful behavior, detrimental and mostly undeclared as well as violation of human rights, and violence may draw women as cultural heritage establishes the perception inferiority of women making man a complete authority of being a male, the Eastern societies are still masculine societies, stated preference in everything despite the fact that Islam has honored women and recommended by the Prophet Muhammad (peace be upon him). Women are the best to family and I am the best for my family, (the family means the wife). However, violence practiced against women takes multiple forms of psychological violence, it appears in verbal violence and non-verbal, physical violence, social violence, sexual violence, health violence and economic violence. But The biggest crime case of women's 
vulnerability to violence, directly or indirectly a condition of pregnancy, which linked violence during pregnancy increase the risk of miscarriage (Abu Said, Mervat, 2012) and prematurity and weight loss for the newborn (Moreno \& Watts, 2011) also affects violence in the psyche of the pregnant woman, in turn it affects the physiological status of the fetus, a pregnant woman need special care because of the change of hormones during pregnancy, making pregnant women to the need of care and attention from health aspects, psychological and physical to, through pregnancy in a good healthy physical and psychological, but the violence inflicted on women does not differentiate in some cases, for the fact that women live a special status with pregnancy or not, and therefore the search in the exposure of pregnant women to violence is necessary because of the effects that result from violence against women, both respects mental or physical, (Sarrey, Helmi 2009) has indicated to the most important psychological effects of violence on Women is losing women's self-confidence, as well as self-esteem, women feeling guilty about work carried out by, frustration and depression. The sense of helplessness. Sense of humiliation and indignity. Not feeling unsecured psychological and mental, disorder in psychological health, loss of a sense of initiative and proactive decision-making.

The social impacts of violence could be a divorcé. The Family disintegration, Misunderstanding, and disorder relations between the husband family and the wife's family. Children drop out of school. Inability of parenting and upbringing balanced social and psychological. Children among families inclination to violence, aggressive and violence among children of violent family.

\subsection{Previous Studies}

(Hammouri and Khawaja) 2009 Conducted a study on violence against pregnant women aimed to identify factors associated with domestic violence against pregnant women, violence conducted more than 351 pregnant women from the Palestinian refugees living in Lebanon, which showed the presence of violence against pregnant women, and found a relationship between violence and educational level, where women with less education is exposed to violence more than most educated, as well as violence associated with the age of pregnancy and unwanted pregnancy.

Also both (Aweys, Gharaibeh, Hourani, 2009) conducted a study on 316 of pregnant women in the city of Irbid northern Jordan, to check the spread of physical violence, verbal and sexual by their husbands during pregnancy respectively, and showed a relationship between violence and pregnancy is not planned. The study also aimed to determine the prevalence of violence against pregnant women conducted on 534 pregnant women in Nigeria, which showed the prevalence of verbal violence by $66.2 \%, 10.8 \%$ exposed to the skin subjected, to $9.5 \%$ slapped, $6.8 \%$ threats of violence, $2.7 \%$ forced her to have sexual intercourse, and the results showed that there is a relationship between low level of education and exposure to violence. (Okour and Alibdarna 2011)

The aim of the study (Alibdarna, 2011) to estimate the prevalence of marital violence against pregnant women in the city of Mafraq northern Jordan, and conducted on 303 women reiterate antenatal clinics showed that physical violence is most prevalent $34.7 \%$, followed by psychological violence $28.1 \%$, social violence $17.5 \%$ and sexual violence $15.5 \%$. The results also show the presence of pressure to have a son, which requires repeating pregnancy to have a baby boy, also study shows results of a relationship between the number of pregnancy and the exposure to violence shows a clear relationship between unplanned pregnancy and exposure to violence.

(Alnsour, Khawaja, Kayyali 2009) The study also aimed to identify the views of women about partner violence also aimed to identify the most common types of violence prevalent in Balqa Governorate in Jordan. The study sample consisted of 356 women who reiterate public health centers, study results showed that $87 \%$ of these women have been subjected to violence during the last 12 months, and the most common type is the emotional violence $47.5 \%$, and women from the country sides are the most vulnerable to violence, and non-working women are more vulnerable to violence, third of the women illustrated why their husband beat them.

The (Ibrahim 2010) study aimed to identify the level of physiological health in women battered, study was conducted on 215 women from reiterate the Centers for Women's Union in five governorates in Jordan, the results showed that the level of physiological health of the study sample was average, and showed a statistically significant differences in the level of physiological health for women Battered attributed to occupational status, where differences was for the benefit of worker women.

\subsection{Study Problem}

The issue of violence against women is a global issue not only to a certain nation, due to gravity and its negative effects on the individual and the community and woman could be exposing during her pregnancy. Many forms of physical and psychological violence, verbal, social, emotional and threat which in turn leads to negative effects on mother and the fetus, where the National Centre for Human Rights in Jordan refers that $15 \%$ of pregnant 
women who reiterate health centers subjected to violence (National Centre for Human Rights, 2010), so the study came to list forms of violence directed against pregnant women in Jordanian society, as will as looking at the effects of violence against Pregnant women whether effects physically, psychological or social as each impacts grave on a pregnant woman and her fetus and displays them to the risks that may continue for a long period of time, which might harm them directly, which may be vulnerable to health risks and emotional.

\subsection{The Importance of the Study and Justification}

Given the interest in the growing global issues of violence against women emerged from the many international treaties and conventions, to claim the rights of women and the elimination of all forms of discrimination against them, this study came to discuss the issue of violence against a pregnant woman for being complementary study to studies of violence against women, which has been narrowed mostly in the study of domestic violence, despite the vulnerability of women to many other aspects of communal violence in its different roles and functions, within the community stemming from the typical image in the social heritage. Where as the pregnant woman has her privacy, particularly when she is exposed to psychological changes and physiological, they need the necessity of care from family members to give birth to healthy sons for the family and the community, if the pregnant women exposed to any form of violence from her husband, it will affect her directly, from here the study highlights the importance of the current lack of studies on the local level, which addressed the issue of violence against women in pregnancy, and the implications of the commission, for it centered justification study including the following:

1) The lack of studies that have examined the issue of violence against a pregnant woman from Sociological point on the Jordanian standard.

2) Lack of information and data on the phenomenon of violence against a pregnant woman, which proves modern subject and justifying studies at all levels.

3) Privacy category pregnant women who are subjected to physical, psychological health conditions and emotional have its effect on the pregnant woman and on her unborn child.

4) The issue of raising attention to this category of society to alert the risk of violence at this stage on woman and her unborn child and her family.

5) To identify some of the factors that increase the likelihood of exposure pregnant women to violence that need to work on necessary preventive programs, may be directed to pregnant women or the husband or the surrounding environment to minimize the exposure of pregnant women to violence.

\subsection{Study Objectives}

The study seeks to achieve the following objectives:

1) Get to the manifestations of violence against a pregnant woman of physical violence, psychological, and social.

2) Knowing the results effects of violence against a pregnant woman (the cost of violence).

3) To identify the most prevalent forms of violence.

4) To identify relationship between some qualitative variables (level of education, housing, income level, family size) and forms of violence against a pregnant woman.

5) Identifying the relationships between some qualitative variables (level of education, housing, income level, family size). And the effects of violence, resulted from the exercising violence against pregnant women.

\subsection{Questions of the Study}

To achieve the objectives of the study, the study seeks to answer the following questions:

1) What are the manifestations of violence against a pregnant woman?

2) What are the implications for the practice of violence against a pregnant woman?

3) Is there a statistically significant difference, at the 0.05 level of significance in the forms of violence against pregnant women are attributable to (education level, place of residence, income level, number of family members)?

4) Are there statistics differences, at the 0.05 level of significance of the effects of violence against pregnant women are attributable to (education level, place of residence, income level, number of family members)? 


\subsection{Procedural Definitions}

Violence: Behavior or an act characterized by aggressiveness comes from an individual, in order to overcome the other side and not exercising their recognized socially rights, and legally within the framework of unequal power relations between the sexes, lead to unequal force to a bodily harm, or psychological, or economical, or legal, or sexual.

Physical violence: Is the use of force by hands or legs as slapping kicking, punching and pulling hair, biting, choking and beating tool.

Psychological violence: Is any violence or behavior based on the abuse in order to undermine the dignity of women or self confidence or her sense of value. One of its forms unjustified criticism, criticism in obscene terms, sarcasm and ridicule, humiliation and the constant use of divorce threats, or deprivation from children, and public humiliation.

Social violence: That means preventing wife's from exercising their social rights, personal rights, and submitted to the husband demands of intellectual, emotional, and trying to limit their involvement in the community and play their role, affecting their stability of emotional and social status, or disallowing from visiting friends and family and intervention with her personal relationships.

Pregnant women: A stage of a woman's life, in which carrying a child inside her, for a period between conception and birth, accompanied by an increase in the mother's abdomen, weight gain and through several stages.

\section{Method}

\subsection{Study Procedures}

Study population: The study population consisted of pregnant women, who reiterate antenatal clinics in the city of Salt which is away from the capital Amman 25 kilometers, during the period from 04/15 th $06 / 02 \mathrm{sec} 2012$ they are four distributed clinics in the Sal city center.

Study sample: The study sample consisted of 230 women and they are pregnant women who reiterate women's clinics that exist in the city of Salt during the search.

Study Tools: In order to achieve the objectives of the study were a literature review related to the subject of the current study, therefore the means study have designed the form of a questionnaire, consisting of three sections, the first contains general characteristics (age, place of residence, educational level, and educational level of the husband, the monthly income of the family, work, chronic diseases, type of residence). The second designed similar to a likeret scale quartet, which consists of (15) paragraph take answers from (always, sometimes, rarely, never) and given weights $(1,2,3,4)$, sequenced. And the third is designed similar to a likeret scale style quintet consists of (9) paragraphs take answers (always, often, sometimes, rarely, never) and given weights $(5,4,3,2,1)$, sequences.

\subsection{Rationing Measure by Verifying Sincerity and Firmness in the Way}

Validity: To verify the veracity of the measure introduced by researchers to 5 judges specialists in sociology, social service and to judge the standard of the paragraphs.

- Honesty internal

(Reliability): (Alvakronbach) coefficient for internal consistency was extracted between the paragraphs of the scale, as the value of Cronbach alpha coefficient between all paragraphs scale forms of violence $(95.2 \%)$, the scale shows the effects of violence on pregnant women $(81.5 \%)$. This suggests a high degree of internal consistency between paragraphs scale and proof of the stability study means.

\subsection{Statistical Treatments}

Statistical methods were used to suit the study variables and questions, through data entry and analysis using the Statistical Package for Social Sciences (SPSS). Where the study used simple statistical methods from averages and frequencies, percentages, and standard deviations, to demonstrate the characteristics of the study sample and variables, and statistics advanced test, analysis of variance T-test and test analysis of variance F-test to demonstrate the differences and implications of statistical variables. 


\section{Study Result}

\subsection{Characteristics of the Study Sample}

Table 1. The distribution of the study sample by social and economic characteristics of the family

\begin{tabular}{llll}
\hline Variable & Variable level & N & Percentage \\
\hline Age & 18-less than20 & 9 & 3.9 \\
& 20-lessof 22 & 52 & 22.6 \\
& 22-less of 24 & 66 & 28.7 \\
Educational level & 24-less of 26 & 103 & 44.8 \\
& Elementary & 18 & 7.8 \\
& Secondary & 71 & 30.9 \\
Residence & Diploma & 58 & 25.2 \\
& Bachelor & 83 & 36.1 \\
Monthly income & Village & 118 & 51.3 \\
& City & 111 & 48.3 \\
Number of children in the family & Badia & 1 & .4 \\
& Less than 400 & 117 & 50.9 \\
& Average 400-1000 & 100 & 43.5 \\
& More than 1000 & 13 & 5.7 \\
& $(1-3)$ & 138 & 60.0 \\
& $(4-6)$ & 74 & 32.2 \\
\hline
\end{tabular}

The results in Table 1, represents the distribution of study sample by social and economic characteristics of the family members of the sample, to be $44.8 \%$. Ranged Between the ages of 22 - less than 24 years, and accounted for the highest percentage in the age group of 24 - less than 26 years accounted for $44.8 \%$. The percentage of people living in cities $48.3 \%$ and those who live in villages $51.3 \%$, and ranged the families income of the study sample with less than $400 \mathrm{JD}$, while the percentage of households whose income level ranges between 400-1000 JD $43.5 \%$ of the total sample individuals study. The percentages of household's have $1-3$ sons of $60.0 \%$, which is the highest rate, and the lowest percentage of those with 9-7 children, including rate of $6.1 \%$.

Table 2. Arithmetic means and standard deviations for the forms of physical violence occurred on pregnant woman in descending order by the arithmetic means of the paragraph

\begin{tabular}{llllll}
\hline Forms of physical violence & No & $\begin{array}{l}\text { Arithmetic } \\
\text { means }\end{array}$ & $\begin{array}{l}\text { Std. } \\
\text { Deviation }\end{array}$ & Percentage & $\begin{array}{l}\text { Intensity } \\
\text { violence }\end{array}$ \\
\hline Stressful home work & 230 & 2.1304 & 1.22579 & $53.26 \%$ & moderate \\
$\begin{array}{l}\text { Carrying heavy things } \\
\text { forced to engage in any forms }\end{array}$ & 230 & 2.0783 & 1.27213 & $51.95 \%$ & moderate \\
sexual relationship & 230 & 1.4217 & .92063 & $35.54 \%$ & low \\
$\begin{array}{l}\text { Beating attempts } \\
\text { Pulling clothes }\end{array}$ & 229 & 1.4017 & .83519 & $35.42 \%$ & low \\
Slapping & 230 & 1.2565 & .67347 & $31.41 \%$ & low \\
Pushing & 230 & 1.2522 & .61769 & $31.30 \%$ & low \\
Hair pulling & 230 & 1.2043 & .55836 & $30.10 \%$ & low \\
Throwing to ground & 230 & 1.2000 & .55603 & $30 \%$ & low \\
Kicking & 230 & 1.1565 & .47819 & $28.9 \%$ & low \\
Punching & 230 & 1.1522 & .45627 & $28.8 \%$ & low \\
Beating with a tool & 230 & 1.1348 & .42221 & $28.37 \%$ & low \\
Throwing incendiary substance & 230 & 1.0826 & .33324 & $27.065 \%$ & low \\
Total score & 230 & 1.0261 & .24587 & $25.65 \%$ & low \\
\hline
\end{tabular}

Table 2 arithmetic means and standard deviations for Answers study sample paragraphs that measure physical 
violence incident on a pregnant woman, for the level of paragraphs notes that doing household chores in cumbersome gained the highest score average (2.1304), followed by carrying heavy objects with an average(2.0783), while the observed convergences in arithmetic mean of the paragraphs related to exercise any form of sexual relationship, and the attempt of beating at the average $(1,417)$, illustrated by data table itself that women who had been kicked, pulling hair, brandishing weapons in their faces and dumping material incendiary, they were less common among the study sample, and this is due to the nature of these forms that it has become difficult to use, and exercise it inside houses due to the seriousness on pregnant woman and her unborn child.

Table 3. Arithmetic means and standard deviations for the forms of psychological violence actually at pregnant women in descending orderly by the arithmetic mean of the paragraph

\begin{tabular}{llllll}
\hline Forms of psychological violence & N & $\begin{array}{l}\text { Arithmetic } \\
\text { means }\end{array}$ & $\begin{array}{l}\text { Std. } \\
\text { Deviation }\end{array}$ & Percentage & $\begin{array}{l}\text { Intensity } \\
\text { violence }\end{array}$ \\
\hline Question about the sex of the baby & 230 & 2.4435 & 1.29622 & $61.08 \%$ & moderate \\
Buying house needs without help & 230 & 1.9435 & 1.11022 & $48.58 \%$ & low \\
Interference in privacy & 230 & 1.9130 & 1.13742 & $47.82 \%$ & low \\
My husband does not take incursion in my & 230 & 1.7087 & 1.08881 & $42.7 \%$ & low \\
mental and volatility & & & & & \\
Neglect & 230 & 1.6348 & 1.00070 & $40.87 \%$ & low \\
Frequent criticism & 230 & 1.6304 & .97476 & $40.76 \%$ & low \\
Swearing & 230 & 1.5435 & .98696 & $38.58 \%$ & low \\
Censure and reprimand & 230 & 1.5217 & .98325 & $38.08 \%$ & low \\
Cursing & 230 & 1.5174 & .96541 & $37.935 \%$ & low \\
Authoritarianism & 230 & 1.4261 & .88718 & $35.65 \%$ & low \\
Insult & 230 & 1.3130 & .78038 & $32.82 \%$ & low \\
Sarcasm & 230 & 1.3087 & .72715 & $32.71 \%$ & low \\
Use obscene words & 230 & 1.3043 & .78383 & $32.60 \%$ & low \\
Divorce threat constantly & 230 & 1.2957 & .78717 & $32.39 \%$ & low \\
Compromising your honor & 230 & 1.2783 & .71231 & $31.95 \%$ & low \\
Abasement & 230 & 1.2391 & .89112 & $30.97 \%$ & low \\
Humiliation & 230 & 1.2087 & .63378 & $30.21 \%$ & low \\
Spitting & 230 & 1.1217 & .76092 & $28.04 \%$ & low \\
Total degree & 230 & 1.5196 & .65735 & $37.99 \%$ & low \\
\hline
\end{tabular}

The psychological violence is the most common type of violence prevalent among women, as shown in Table No. (3) arithmetic means and standard deviations by exposure to forms of psychological violence, as it seems from the answers respondents that more forms of psychological violence occurred, which appears in the continued question about the chilled gender by average (2.4435), followed by its purchase needs home without the help of others by average (1.94), the neglect and criticism frequent and insults of shapes, are scattered among the study sample as converged arithmetic mean (1.63), and the same paragraphs that contained of abasement, humiliation, spitting less degrees of approval, were averages respectively(1.20) and (1.12). This is consistent with the theory of frustration in its interpretation of violence

Table 4. Arithmetic means and standard deviations for forms of social violence, actually pregnant woman in descending order by the arithmetic mean of the paragraph

\begin{tabular}{|c|c|c|c|c|c|}
\hline Forms of social violence & $\mathbf{N}$ & $\begin{array}{l}\text { Arithmetic } \\
\text { means }\end{array}$ & $\begin{array}{l}\text { Std. } \\
\text { Deviation }\end{array}$ & Percentage & $\begin{array}{l}\text { Intensity } \\
\text { violence }\end{array}$ \\
\hline $\begin{array}{l}\text { I feel people respect me if I' am pregnant } \\
\text { with a boy }\end{array}$ & 230 & 1.9826 & 1.25717 & $49.56 \%$ & low \\
\hline The exposure to smoking constantly & 230 & 1.7783 & 1.16291 & $44.45 \%$ & low \\
\hline $\begin{array}{l}\text { Carrying a female make my husband less } \\
\text { interest in me }\end{array}$ & 230 & 1.4174 & .92969 & $35.43 \%$ & low \\
\hline $\begin{array}{l}\text { Threat to marry another if my pregnancy } \\
\text { was a female }\end{array}$ & 230 & 1.2609 & .78842 & $31.52 \%$ & low \\
\hline Not allowed to review the Doctor & 230 & 1.1913 & .58206 & $29.78 \%$ & low \\
\hline Not allowed to buy my medicine & 230 & 1.1826 & .58485 & $29.56 \%$ & low \\
\hline Total degree & 230 & 1.4688 & .67020 & $36.7 \%$ & low \\
\hline
\end{tabular}


The data in Table 4 describes arithmetic means and standard deviations for the forms of social violence incident on pregnant women, where it appears that the treatment of people towards pregnant women is different, if the baby is male, it won the highest approval average (1.98), and exposure to smoking by a husband without indifference seriousness of smoking, while the observed convergence in arithmetic mean of the paragraphs related by not allowing them to review their doctor regularly, and buying the necessary medicines, and the husband carelessness. If the born was a female, average $(1,417)$, the results showed that the threat of a husband to marry again for carrying a Female was clear, this is due to the culture of the community, and the study emphasizes (Ali Bdarna, 2011)that the sex of the baby and the existence of this is a form of violence.

Table 5. Arithmetic means and standard deviations for the psychological effects of violence actually at pregnant women in descending order by the arithmetic mean of the paragraph

\begin{tabular}{|c|c|c|c|}
\hline Psychological effects & $\mathbf{N}$ & means & Std. Deviation \\
\hline Psychological stress and anxiety & 229 & 3.7729 & 1.30147 \\
\hline Depression & 230 & 3.6957 & 1.38409 \\
\hline $\begin{array}{l}\text { Psychological physical systems (headache ,stomachache, colitis, } \\
\text { nerves, and emotionalist }\end{array}$ & 230 & 3.6478 & 1.32572 \\
\hline Lack of concentration & 230 & 3.3478 & 1.42983 \\
\hline Physical illness & 229 & 3.1528 & 1.48627 \\
\hline Isolation & 230 & 3.1000 & 1.43977 \\
\hline Freeze of emotions & 230 & 3.0870 & 1.55855 \\
\hline Giving birth before time & 230 & 2.7174 & 1.38399 \\
\hline Miscarriage & 230 & 2.6609 & 1.45612 \\
\hline Newborns with little weight & 230 & 2.6435 & 1.42155 \\
\hline Suicide thinking & 230 & 2.1174 & 1.48034 \\
\hline Total degree & 230 & 3.0826 & 1.08979 \\
\hline
\end{tabular}

Table 5 shows arithmetic means and standard deviations for the effects of psychological located on pregnant women, where it appears from the answers respondents that tension, anxiety and depression are the most psychological effects that pregnant woman suffers, whether its pregnancy nature and physiological changes or actions from the husband who does not take into account psychological of the wife, a Arithmetic mean (3.77), followed by exposure to symptoms psychosomatic headaches and upset stomach and colon resulted of husband violence by average (3.6478), followed by lack of concentration and physical illness and isolation by average (3.15), while showed that suicidal ideation less degrees approved by average (2.11), and these an expected results for women subjected to violence, especially during pregnancy.

Table 6. Averages and standard deviations of the effects of social violence subjected at pregnant women in descending order by the arithmetic mean of the paragraph

\begin{tabular}{lrrc}
\hline \multicolumn{1}{c}{ The effects of social violence } & N & means & Std. Deviation \\
\hline Not performing toward the family because of stress and fatigue & 229 & 3.2926 & 1.45608 \\
slackening at house shores & 229 & 3.2358 & 1.40373 \\
Illumination on social relationships & 228 & 3.1272 & 1.41936 \\
The impact on the delivery & 230 & 2.9826 & 1.49808 \\
Family matters with the husband family & 229 & 2.9563 & 1.54687 \\
Taking absence from work & 229 & 2.5852 & 1.55257 \\
The long absence from work & 229 & 2.3231 & 1.48100 \\
Total degree & 230 & 2.9161 & 1.18624 \\
\hline
\end{tabular}

The table data show averages and standard deviations of the social effects experienced by pregnant women, as the inability to perform their duties because of the continued social tensions, Arithmetic average (3.29), followed by failing to household chores by average (3.13), followed by reduction of relations social as a result of violence exercised by the pair by average (3.12), and the existence of an ongoing family problems with the 
husband's family by average (2.92), the Feminist theory has interpreted women suffering from these effects because of the traditional expectations of the woman role and supports the social construction of the control of the pair.

Table 7. Averages and standard deviations and $\mathrm{T}$ test results to examine the differences in the forms of violence that are attributed at housing

\begin{tabular}{llllllll}
\hline Form of violence & $\mathrm{N}$ & Residency & $\mathrm{M}$ & $\mathrm{Sd}$ & $\mathrm{T}$ & $\mathrm{df}$ & $\mathrm{sig}$ \\
\hline Physical & 118 & City & 1.2953 & .43560 & 1.667 & 228 & .097 \\
& 112 & Village & 1.3984 & .50121 & & & \\
Psychological & 118 & City & 1.4449 & .62460 & 1.776 & 228 & .077 \\
& 112 & Village & 1.5982 & .68416 & & & \\
Social & 118 & City & 1.4138 & .58134 & 1.279 & 228 & .202 \\
& 112 & Village & 1.5268 & .75089 & & & \\
\hline
\end{tabular}

Table 7 shows there is no significant statistically differences at the level $(\mathrm{a}=0.05)$ in physical, psychological and social against pregnant women due to variable place of residents, that indicates that pregnant women are exposed to the similar degree of physical ,psychological and social violence whether she was from the village or the city.

Table 8. Arithmetic means and standard deviations of forms of violence against pregnant women due to the variable family monthly income

\begin{tabular}{lllll}
\hline Forms of violence & Level income & $\mathrm{N}$ & Mean & Std. Deviation \\
\hline Physical & Below 400 & 117 & 1.3761 & .50409 \\
& From 400-1000 & 100 & 1.2808 & .39472 \\
& More than 1000 & 13 & 1.5680 & .62060 \\
Psychological & Total & 230 & 1.3455 & .47051 \\
& Below 400 & 117 & 1.5679 & .68796 \\
& From 400-1000 & 100 & 1.4167 & .57086 \\
Social & More than 1000 & 13 & 1.8761 & .85652 \\
& Total & 230 & 1.5196 & .65735 \\
& Below 400 & 117 & 1.4658 & .67542 \\
& From 400-1000 & 100 & 1.4200 & .58530 \\
& More than 1000 & 13 & 1.8718 & 1.06752 \\
& Total & 230 & 1.4688 & .67020 \\
\hline
\end{tabular}

Table 8 shows Arithmetic means and standard deviations to examine the different forms of violence against pregnant women due to the variable monthly income. It was found that pregnant women is exposed to psychological violence in families with income below $400 \mathrm{JD}$, with an average (1.56), in return the psychological violence average to words pregnant women in families with income over (1000) JD reached (1.8761), and differences are evidential in the forms of violence against pregnant women due to the variable monthly income in table 9 .

Table 9. Averages and standard deviations and F test results to examine the differences in the forms of violence that is attributable to variable monthly income

\begin{tabular}{lllllll}
\hline Violence forms & Source & SS & df & MS & F & Sig \\
\hline \multirow{3}{*}{ Physical } & Between Groups & 1.172 & 2 & .586 & & \\
& Within Groups & 49.523 & 227 & .218 & 2.687 & .070 \\
& Total & 50.695 & 229 & & & \\
psychological & Between Groups & 2.984 & 2 & 1.492 & & \\
& Within Groups & 95.968 & 227 & .423 & 3.530 & $.031^{*}$ \\
& Total & 98.952 & 229 & & & \\
Social & Between Groups & 2.350 & 2 & 1.175 & & \\
& Within Groups & 100.510 & 227 & .443 & 2.654 & .073 \\
\hline
\end{tabular}

Table 9 shows the statically significant difference, at the level $(\mathrm{a}=0.05)$ in the psychological violence on 
pregnant women due to the variable level of monthly income of the family, and to find out the sources of differences, a test has been taken orally for dimensional comparisons , as shown in the following table.

Table 10. Oral Tests results comparisons posteriori averages for pregnant women due to the variable level of family income

\begin{tabular}{lll}
\hline Income Level & From $(400-1000)(\mathrm{m}=1.5679)$ & More than $1000 \mathrm{~m}=(1.4167)$ \\
\hline Less than $400(\mathrm{~m}=1.8761)$ & .3082 & $.4594^{*}$ \\
From $400-1000$ & - & .1512 \\
\hline
\end{tabular}

Table 10 shows the differences between the average psychological violence among pregnant women from families with a monthly income of less than (400) JD, and between the average psychological violence among pregnant women from families whose monthly income over (1000) JD have reached (0.4594), and its significant statistically difference at the level of $(\alpha=0.05)$ and for pregnant women with families with incomes below (400) JD per month, and it suggests that pregnant women who belong to families with the least monthly income (400) JD are more vulnerable to psychological violence from pregnant women who belongs to the families their monthly income more than (1000) JD.

Table 11. Averages and standard deviations and F test results to examine the differences in the forms of violence that is attributed to the wife educational level

\begin{tabular}{lllllll}
\hline Form of violence & & Sum of Squares & Df & Mean Square & F & Sig. \\
\hline \multirow{3}{*}{ Physical } & Between Groups & .969 & 3 & .323 & 1.467 & .224 \\
& Within Groups & 49.727 & 226 & .220 & & \\
& Total & 50.695 & 229 & & & \\
Psychological & Between Groups & 2.133 & 3 & .711 & 1.659 & .177 \\
& Within Groups & 96.819 & 226 & .428 & & \\
& Total & 98.952 & 229 & & & \\
Social & Between Groups & 1.994 & 3 & .665 & & 1.489 \\
& Within Groups & 100.866 & 226 & .446 & & \\
& Total & 102.860 & 229 & & &
\end{tabular}

It appears from table 10 there is no statistically significant differences at the level of $(\alpha=0.05)$ in the forms of psychological violence and physical and social attributable to the (educational level) where all values (F) of the forms of violence against a pregnant woman is not statistically significant. This means that the physical and psychological violence and social practices to all educated women and uneducated. This may be due to the fact that violence makes the individual not to think to whom surround him, because violence is a form of rage and aggression, loses its perpetrator to control his temper, and this promotion to Psychoanalytic theory to engage in violence when (Freud) as mentioned earlier, this result does not agree with results of (Hammouri Khawaja 2007) study, (Okour and Alibdarna 2011) study that showed that women with less education are more vulnerable to violence.

Table 12. Averages and standard deviations and $\mathrm{F}$ test results to examine the differences in violence effects against pregnant women due to the level of the wife education

\begin{tabular}{lllllll}
\hline Sparked violence & Source variation & Sum of Squares & Df & Mean Square & F & Sig. \\
\hline Psychological & Between Groups & 8.907 & 3 & 2.969 & 2.551 & .057 \\
& Within Groups & 263.064 & 226 & 1.164 & & \\
& Total & 271.970 & 229 & & & \\
Social & Between Groups & 16.969 & 3 & 5.656 & 4.188 & $.007^{*}$ \\
& Within Groups & 305.271 & 226 & 1.351 & & \\
& Total & 322.240 & 229 & & & \\
\hline
\end{tabular}

The results of Table 11 the analysis results of variance to test for differences in the psychological and social suffering of pregnant women because of the violence, actually upon her by the husband due to the variable level of education by using T-test, where the results showed that there is significant differences at the educational 
level(alpha $=0.05)$ and find out that the sources of these differences has been applied methods (Scheffe) for comparisons dimensional, where the sources showed the differences were between levels (primary, secondary, Diploma, Bachelor and above) for the benefit of women who received standard education bachelor degree, or suffers more from the effects of psychological and social as a result of violence from the husband, and this shows educated women as a result of their awareness can distinguish behaviors that is violence against them, so they are the most affected by violence upon her.

\section{Discussion of Results}

the study results indicated that pregnant women exposed to many forms of physical violence as the doing housework cumbersome without the help of others, and carrying heavy objects received the highest score by average (2.13), and it seems that women who were forced to practice sexual relationship against their will were the most common among the Arithmetic mean $=(1.42)$, followed by the attempt of beating by the average (1.40), the results illustrated of the study, women who had been kicked, pulling hair, brandishing weapons in their faces and dumping material incendiary they were the less common among the study sample. This reflects the cultural of the society that does not recognize the role of the girl only marital home and multiple responsibilities that are not exempt specific health conditions.

The psychological violence is the most types of violence prevalent among pregnant women for the study sample, where frequent questioning about sex of the baby is the most common and prevalent among the study sample average (2.44), especially to their preference of male or female that's compatible with the study (Okour and Albadranh, 2011), which confirmed that Pregnant women exposed to psychological pressure by carrying a female, as well as the presence of pressure to have a son, which requires to repeat pregnancy to have a male, and it appears from the results of the study that pregnant women suffer from stress due to the neglect of the husband, and adopted them through its responsibilities as buying home needs without assistant of other to her. The neglect and criticism continues from which are prevalent among the study sample as arithmetic average (1.63), and the repeated picture in criticizing women in terms of shape, slow movement and other things that may reprove women psychologically, which may limit their freedom and increases the shed of men over women, and the paragraphs of abasement, spitting and humiliation least prevalent among the study sample. The point view of people to pregnant women rate the differs if the born is a female, convergence of attention and care and respect if the baby is a male, in turn this affects women and considered forms of social violence according to the study sample Arithmetic mean (1.42), and the longer exposure to second-hand smoke the most prevalent among the study sample Arithmetic by the average (1.77). In addition, the divorce threat of violence most prevalent among social members of the study sample.

As results showed the consequences of physical violence, psychological and social on pregnant women, so that epitomized the cost of being harmed to be psychological stress and constant worry a mean of (3.77), and Arithmetic average to those who experienced symptoms psychosomatic by (3.64), and who felt depressed by (96.3), and who have been subjected to physical illness, poor concentration and isolation from the family by (3.34), and the aforementioned factors harmful and negative effects on pregnant women in terms of undermining the health and physical condition. This in turn is reflected in the performance and efficiency within the home and in workplace and society. In addition it reflects on the relationship with her children and family. The Failure in performing household duties, and neglect. The pregnant women show response to violence with extreme concern, emotional isolation and social, so resort victims of violence to drugs or alcohol or smoking in a vain attempt to mitigate or eliminate these symptoms, in addition to that, there are aspects to be associated with the psychological disorder that happens after the violence, and these aspects are behavioral symptoms present when the victim is include shame, self blame, into submission, and a sense of how little events and contempt of self, and aversion sexual, lack of management, resistance, repeated exposure to violence, weak social status and economic, as well as anger, denial and grief with continuity contact with victims of violence. The pregnant women inability to establish social relationships with others was one of the results of social violence directed against them, and to engage in ongoing family problems as a result of persistent tension due to violence reality.

The results showed that there is no statistically significant differences at $(\mathrm{a}=0.05)$ in the physical, psychological and social against pregnant women due to the variable place of residence, which refers the exposure of pregnant women, whether they are living at the village or the city to a closely point to physical violence, psychological and social, and that contrast with (Alnsour) studies were the results shows that women from the village are more vulnerable to violence.

And showed the results of analysis of variance to tests for differences between the averages of forms of physical, psychological and social exposed to pregnant women due to the variable level of education, there is no 
statistically significant differences between the averages and this means that violence against pregnant women in all its forms is practiced at all educated women and uneducated may be due, so that the incidence of violence makes the individual does not think to who surrounded him, because the violence is in the form of rage and aggression, the perpetrator loses control over his temper, and this promotion of Psychoanalytic theory to engage in violence when (Freud) as mentioned above. Nor result is consistent with (Hammouri Khawaja) study, show a relationship between violence and educational level where women with less education are exposed to violence more than most educated.

The results of the analysis of variance to tests for differences between the averages and test results $(F)$ to examine differences in the forms of violence against a pregnant woman, due to the variable monthly income, also no differences in the forms of physical violence and social due to the variable level of income, while results showed in the same table and no differences in psychological violence due to the variable level of income, where the sources differences were between the level of the difference in favor of the level of low-income, means that low-income were more used to psychological violence, as rising level of violence against a pregnant woman down the economic level of the family, (UNIFEM, 2004), where the low level economic such as the provision of medicine, and checking with your doctor, on the one hand as well as psychological stress resulting from frustration leading to a state of psychological tension which is reflected on the marital relationship and the incidence of violence against women in pregnancy.

Also showed the results of analysis of variance to test for differences between the averages of the psychological and social suffering of pregnant women, because of the actually violence and which are attributable to the level of education, and there were statistically significant differences at the level of (0.05) for the benefit of women with a bachelor's degree as an educated woman subjected to violence, which the holder affected socially because of their awareness of what is happening around, especially as the man worked to undermine the freedom of women, and the results show no statistically significant differences at the level of $(\alpha=0.05)$ in the forms of violence against a pregnant woman due to a variable number of individuals where all values $(F)$ of the forms of psychological and physical violence and social against pregnant women depending on the variable (the number of family members) is not statistically significant.

\section{References}

Abu Said, M. A. R. (2010). Relationship problem-solving skills and anger management with violence wives in Jordan, a paper presented at a conference of legal protection for the family between reality and ambition. Amman Private University, Jordan.

Alauwadh, A. (2002). Violence against the wife in the Jordanian society, library dawn. Jordan. World Health Organization.

Ali Bdarna, R. A. L. (2011). Violence Almzle during pregnancy, a paper presented at the World Day of Social Action, 7/4/2011, Amman, Jordan.

Al-Nsour, M., Khawaja, M., \& Al-Kayyali, G. (2009, June). Domestic violence against women in Jordan: evidence from health clinics. Journal of Family Violence, 24, 569-575. http://dx.doi.org/10.1007/s10896-009-9255-2

Arwa Oweis, M. G., \& Alhourani, R. (2010). Prevalence of Violence During Pregnancy: Findings from a Jordanian Survey. Maternal and Child Health Journal, 14(3), 437-445. http://dx.doi.org/10.1007/s10995-009-0465-2

Azeez, K. (2005). The philosophical foundations of Western feminist thought. Beirut: Nissan for publication and distribution.

Brinkerhoff, D. (1997). Sociology. New York: Wads Worth Publishing Company.

Garcia-Moreno, C., \& Watts, C. (2011). Violence against women: an urgent public health priority. World Health Organization. Bulletin of the World Health Organization. http://dx.doi.org/10.2471/BLT.10.085217

Ghanem, A. A. G. (2000). Crimes of violence and ways of confrontation. Naif Arab University for Security Sciences. Riyadh, Saudi Arabia.

Gharaibeh, F. (2012). Social work with families and children. Dar Wael. Amman, Jordan

Giddens, A. (2009). Sociology (6th ed.). UK: Polity press. 
Hammoury, N., Khawaja, M., Mahfoud, Z., Afifi, R. A., \& Madi, H. (2009). Domestic violence against women during pregnancy "the case of Palestinian refugees attending an antenatal clinic in Lebanon". J Womens Health (Larchmt), 18(3), 337-345. http://dx.doi.org/10.1089/jwh.2007.0740

Ibrahim, N. B. (2010, June). Mental Health in battered women in Jordan. Journal of the Islamic University, 8(10), 299-329.

Jazi, H. M. (2005). Domestic violence in the southern desert in Jordan, Master Thesis, University of Mutah, Karak, Jordan.

Kronemann, M. (1981). Modern feminist theory. In Norma, G., \& Patricia, G. (Eds.), Australian Woman feminist perspectives. New York: Oxford university press.

National Council for Family Affairs. (2005). Health and violence. Jordan, Oman.

National Council for Family Affairs. (2008). The reality of violence against women in Jordan. Jordan, Oman.

Okour, A. M., \& Badarneh, R. (2011). Spousal Violence against pregnant women from a Bedouin community in Jordan. Journal of women's health, (20), 1853-1859. http://dx.doi.org/10.1089/jwh.2010.2588

Qamar et al. (2008). Contemporary social problems. thought Jordan House.

Surrey, H. (2009). The Psychological and social effects and economic violence families. Journal of Social Sciences. Retrieved from http://www.swmsa.net

UNIFEM. (2004). The United Nations Development Fund for Women, the progress of Arab women. Jordan, Oman.

Walter, M. O. (1997). Domestic violence. Naif Arab Academy for Security Sciences, Riyadh. 